\title{
KONSTRUKSI DAN PRODUKTIVITAS RUMPON PORTABLE DI PERAIRAN PALABUHANRATU, JAWA BARAT
}

\section{CONSTRUCTION AND PRODUCTIVITY OF PORTABLE FISH AGGREGATING DEVICE IN PALABUHANRATU WATERS, WEST JAVA}

\author{
Roza Yusfiandayani ${ }^{1}$, Indra Jaya ${ }^{2}$, Mulyono S. Baskoro ${ }^{1}$ \\ ${ }^{1}$ Departemen Pemanfaatan Sumberdaaya Perikanan \\ ${ }^{2}$ Departemen Ilmu dan Teknologi Kelautan \\ Fakultas Perikanan dan Ilmu Kelautan, Institut Pertanian Bogor \\ Korespondensi : ochaipb@gmail.com
}

\begin{abstract}
Fish Aggregating Device (FAD) usually used by small and large scale fishermen in Indonesia are FAD shallow and deep sea water which fix in the water. Effectiveness and efficiency research activity about portable FAD in the water to catch Thunnus spp. and skipjack have never been done in Indonesia. This research divided into two stages : portable FAD design, fishing trial with portable FAD used handline and troll line in Palabuhanratu waters. The purpose of this research was to make portable FAD design, fishing trial used Electric Fish Attractor (EFA) with different frequency and to compared effectiveness of catch composition with handline and troll line. The result of this study were design FAD portable with length and width $1 \mathrm{~m}$, the material is manglid wood, the attractors are raffia line and attractor and sinker line used PE with diameter $4 \mathrm{~mm}$ and tin sinker, EFA with frequency 10-1.000 Hz catch Caranx fasciatus and Trichiurus sp., whereas EFA with frequency 1.000-20.000 Hz catch 2 fish of Thunnus albacares with length $30 \mathrm{~cm}$ and weight $40 \mathrm{~kg}$, catch composition used handline was Trichiurus sp. 63\%, Nemiptarus sp. 10\%, Caesio cuning 7\%, Euthynnus spp. and semar 4\%, Lutjanus spp. and Thunnus albacares $2 \%$, whereas catch composition with troll line was Rastrelliger spp, Caesio cuning and Selaroides spp. $1 \%$.
\end{abstract}

Keywords: Electric Fish Atractor, Palabuhanratu, portable Fish Aggregating Device, Thunnus albacares

\begin{abstract}
ABSTRAK
Rumpon yang biasa digunakan oleh nelayan dan pengusaha di seluruh Indonesia adalah rumpon yang dipasang menetap di suatu perairan, sehingga tidak dapat dipindah-pindah ke perairan lain. Sejauh ini di Indonesia belum pernah dilakukan penelitian tentang efektivitas dan efisiensi rumpon yang dapat dibawa kemana-mana dan mudah dipindahkan (portable) untuk menangkap ikan tuna dan cakalang. Penelitian ini dibagi dalam 2 tahap : pembuatan desain instrumen rumpon portable, uji coba rumpon portable dan Electric Fish Attractor (EFA) di perairan Palabuhanratu dengan menggunakan pancing gajrut dan tonda. Tujuan dari penelitian ini adalah: merancang dan membuat prototipe desain dan konstruksi rumpon portable yang dapat mengumpulkan ikan, uji coba electric fish attractor dengan frekuensi suara yang berbeda, serta membandingkan efektivitas hasil tangkapan dengan menggunakan alat tangkap pancing tonda dan pancing gajrut. Hasil penelitian ini adalah prototipe rumpon portable memiliki ukuran panjang dan lebar sebesar 1 meter, bahan yang digunakan kayu manglid, atraktor yang digunakan tali rafia, tali atraktor dan tali pemberat adalah tali PE berdiameter $4 \mathrm{~mm}$ serta pemberat timah, EFA dengan frekuensi 10-1000 Hz mendapatkan ikan kuwe (Caranx fasciatus) dan ikan layur hitam (Trichiurus sp.), sedangkan EFA dengan frekuensi 1000-20.000 Hz mendapatkan ikan tuna sirip kuning, Thunnus albacares sebanyak 2 ekor dengan ukuran panjang $30 \mathrm{~cm}$ dengan berat $40 \mathrm{~kg}$, Hasil tangkapan dengan pancing gajrut memiliki komposisi hasil tangkapan ikan Trichiurus sp. 63\%, Nemiptarus sp. 10\%, Caesio cuning 7\%, Eutbynnus spp. and semar 4\%, Lutjanus spp. and Thunnus albacares $2 \%$ sedangkan dengan pancing tonda komposisinya ikan kembung, ekor kuning, selar kuning dan selar hijau masing-masing $1 \%$.
\end{abstract}

Kata kunci: electric fish atractor, Palabuhanratu, rumpon portable, Thunnus albacares 


\section{PENDAHULUAN}

\section{Latar Belakang}

Rumpon merupakan alat bantu dalam penangkapan ikan. Peraturan Menteri Kelautan dan Perikanan, Nomor PER 02/MEN/2011 mendefinisikan rumpon sebagai alat bantu untuk mengumpulkan ikan dengan menggunakan berbagai jenis atraktor dari benda padat yang berfungsi untuk memikat ikan agar berkumpul. Teknologi rumpon saat ini sudah semakin banyak dikembangkan, salah satunya ialah rumpon portable.

Rumpon portable merupakan rumpon yang tidak diletakkan secara tetap di perairan, tetapi diletakkan pada saat akan melakukan kegiatan penangkapan ikan di daerah penangkapan ikan tersebut. Ketika tidak digunakan, rumpon tersebut dapat dibawa atau dipindahkan ke daerah lain atau disimpan hingga dilakukan operasi penangkapan ikan selanjutnya (Yusfiandayani 2013). Rumpon portable dimaksudkan untuk mengumpulkan ikan yang berasosiasi pada rumpon, lalu ikan tersebut ditangkap oleh nelayan Palabuhanratu menggunakan pancing ulur. Pancing ulur (hand line) merupakan salah satu jenis alat penangkapan ikan yang sering digunakan oleh nelayan Palabuhanratu untuk menangkap ikan di laut. Pancing ulur termasuk alat tangkap ikan aktif dan juga ramah lingkungan. Berdasarkan klasifikasi DKP tahun 2008, pancing ulur termasuk dalam klasifikasi alat tangkap hook and line. Struktur utama dari alat tangkap pancing ulur terdiri dari mata pancing, swivel, tali pancing, pemberat serta umpan. Jenis pancing ulur yang digunakan dalam penelitian ini menggunakan 3 tali cabang dan mata pancing dipasang pada masing-masing tali cabangnya. Mata pancing yang digunakan yakni mata pancing tunggal dengan nomor 7. Secara keseluruhan bagian-bagian pancing ulur dalam penelitian ini terdiri dari tali utama/main line menggunakan bahan nilon polyamide (PA) monofilament No. 1200, sebuah kili-kili, tali cabang/branch line menggunakan bahan nilon polyamide (PA) monofilament No. 400, dan pemberat timah $1 \mathrm{~kg}$. Jenis umpan menggunakan umpan buatan dari serat sutra berwarna merah keperak-perakan. Penelitian ini menggunakan 3 unit alat tangkap pancing ulur yang dibedakan panjang dan jarak tali cabang/branch line antar alat tangkap. Adapun panjang dan jarak branch line yang digunakan berukuran $0.90 \mathrm{~m} ; 1.20 \mathrm{~m}$; dan $1.50 \mathrm{~m}$.

Secara garis besar rumpon, baik rumpon laut dalam maupun rumpon laut dangkal pada prinsipnya terdiri dari empat komponen utama, yaitu: (1) pelampung atau float; (2) tali panjang atau rope; (3) pemikat ikan atau atractor dan (4) pemberat atau sinker. Rumpon yang portable merupakan rumpon yang tidak diletakkan secara tetap di perairan, tetapi diletakkan pada saat akan melakukan kegiatan penangkapan di daerah penangkapan ikan tersebut, sehingga ketika tidak digunakan, dapat dibawa, dipindahkan ke daerah lain atau di simpan sampai dilakukan operasi penangkapan ikan selanjutnya.

Penelitian ini didasari oleh produksi perikanan tuna dan cakalang berbasis rumpon yang terus menurun dengan ketersediaan sumberdaya yang terbatas dan daerah penangkapan tuna dan cakalang yang semakin jauh, sementara upaya pemanfaatan semakin meningkat sehingga dipandang perlu adanya pengelolaan yang baik dan berkelanjutan yang memberikan keuntungan usaha penangkapan ikan tuna. Berdasarkan permasalahan tersebut di atas maka dianggap perlu untuk mengkaji pembuatan rumpon portable yang mudah dibawa kemana-mana dan tingkat kelayakan pemanfaatan rumpon dan optimalisasi armada penangkapan yang beroperasi di sekitar rumpon agar produktivitas optimum dapat terjaga.

Dasar pertimbangan yang menjadi kerangka pemikiran adalah peningkatan pemasangan rumpon yang menyebabkan peningkatan aktivitas penangkapan di lokasi penelitian yang mengakibatkan terjadinya penurunan hasil produksi sehingga dianggap perlu adanya pengelolaan pemanfaatan secara optimal dengan menitik beratkan pada masalah jumlah rumpon dan alat tangkap yang beroperasi di sekitar rumpon.

Oleh karena itu, pengkajian terhadap rumpon portable untuk pengelolaan ikan tuna dan cakalang secara berkelanjutan dalam mengantisipasi implementasi Code of Conduct for Responsible Fisheries ini perlu dilakukan. Rumpon portable memiliki keuntungan: 1) mudah dibawa dan ditempatkan di perairan; 2) dapat menjangkau ke perairan yang lebih jauh tanpa memerlukan biaya yang besar; dan 3) memudahkan operasi penangkapan ikan. Penelitian ini diharapkan dapat memperkuat Sistem Inovasi Nasional dengan adanya rumpon portable yang memudahkan nelayan, informasi geospasial daerah penangkapan ikan yang bermanfaat bagi armada penangkapan serta informasi mengenai carrying capacity rumpon di suatu daerah penangkapan ikan sebagai komponen informasi dasar yang strategis dalam membantu merumuskan kebijakan pengelolaan berkelanjutan sumberdaya ikan. Tujuan penelitian ini adalah merancang dan membuat prototipe desain dan konstruksi rumpon portable yang dapat menarik ikan untuk berkumpul, merancang dan uji coba electric fish attractor dengan frekuensi suara yang berbeda, membandingkan efektivitas hasil tangkapan dari penggunaan rumpon portable dengan menggunakan alat tangkap pancing.

\section{METODE PENELITIAN}

Penelitian ini dilakukan 
Palabuhanratu pada bulan Agustus 2013 (Gambar 1).

Alat dan bahan yang digunakan dalam penelitian ini dibagi menjadi peralatan yang digunakan untuk uji coba lapang serta alat dan bahan yang digunakan dalam pembuatan rumpon portable. Peralatan yang digunakan untuk uji coba lapang adalah kapal, plankton net, tali tambang, GPS, hand camera, alat tangkap yaitu pancing gajrut dan pancing tonda untuk menangkap ikan tuna dan cakalang. Peralatan yang digunakan tersebut pengadaannya dilakukan secara langsung dari laboratorium dan dari nelayan bersangkutan yang ikut membantu penelitian ini (Tabel 1). Penelitian ini dibagi dalam 2 tahap: pembuatan desain instrumen rumpon portable, electric fish attractor dan uji coba skala laboratorium dan uji coba rumpon portable dan electric fish attractor di perairan Palabuhanratu dengan experimental fishing menggunakan pancing gajrut (handline) dan tonda untuk menangkap ikan tuna.



Gambar 1. Peta lokasi penelitian

Tabel 1. Alat dan bahan perakitan EFA

\begin{tabular}{cll}
\hline No & \multicolumn{1}{c}{ Alat } & \multicolumn{1}{c}{ Bahan } \\
\hline 1 & MP3 player + Amplifier & Sambungan pipa T + Penutup \\
2 & Laptop & Paralon 5 inch \\
3 & Speaker Audax 4 inch & Silicon glass sealant \\
4 & Accu 12 volt & Resin, Katalis, Mat \\
5 & SD card dan Card reader & Selotip \\
6 & Gunting dan penggaris & Amplas \\
7 & Gergaji pipa & Lem pipa \\
8 & Buku dan pulpen & \\
\hline
\end{tabular}

Tabel 2. Alat dan bahan pada uji coba lapang

\begin{tabular}{cll}
\hline No & \multicolumn{1}{c}{ Alat } & Bahan \\
\hline 1 & Timbangan digital & Selotip \\
2 & Pisau bedah & Tali rafia \\
3 & Meteran & Tali tambang \\
4 & Alat tulis, Penggaris & Formalin $10 \%$ \\
5 & GPS & Cairan lugol \\
6 & Gunting & Plastik $1 \mathrm{~kg}, 3 \mathrm{~kg}$ dan $5 \mathrm{~kg}$ \\
7 & Kamera & Botol film \\
8 & Laptop & \\
\hline
\end{tabular}


Berdasarkan waktu pengoperasiannya penelitian ini mengambil empat waktu operasional dalam satu hari, waktu operasional kesatu (I) dilakukan operasi tiga unit alat tangkap pada pukul 05:0008:00 WIB, waktu operasional kedua (II) dilakukan satu jam berikutnya yakni pukul 09:00-11:00 WIB, waktu operasional ketiga (III) dilakukan pukul 13:00-15:00 WIB, serta waktu operasional alat tangkap pancing ulur yang keempat (IV) dilakukan dari pukul 15:00-18:00 WIB.

\section{HASIL DAN PEMBAHASAN}

\section{Rumpon portable}

Rumpon portable yang dibuat mampu digunakan secara fleksibel karena mudah dibawa dan mudah dalam pengoperasiannya. Pembuatan satu unit rumpon dimulai dengan membuat rangka rumpon yang terbuat dari koper yang berukuran $\mathrm{p} x 1$ : 3 x $2.50 \mathrm{~m}$, rangka rumpon kemudian dilapisi dengan stainless steel sehingga membentuk rangka yang berukuran $\mathrm{p} \times 1 \times \mathrm{t}: 3 \times 3 \times 2.50$ m (Gambar 2) rumpon tertutup. Rumpon portable yang dioperasikan di perairan dapat dilihat pada Gambar 3. Pengisian sterofoam cair pada bagian dalam rumpon bertujuan sebagai pelampung. Electric fish atractor dikaitkan pada tali selambar dengan kedalaman $2 \mathrm{~m}$ dari permukaan air dengan atraktor berupa tali rafia yang dipasang setiap $50 \mathrm{~cm}$.

Prototipe rumpon portable yang telah selesai dirakit, diuji coba daya apung dan daya tenggelam dengan menggunakan air tawar di watertank Laboratorium Akustik Departemen Ilmu dan Teknologi Kelautan, Fakultas Perikanan dan Ilmu Kelautan, Institut Pertanian Bogor. Perhitungan daya apung dan daya tenggelam juga dilakukan di perairan Palabuhanratu. Perhitungan mengenai bouyancy dan extra bouyancy dari rumpon portable pada air tawar dan air laut yang ditampilkan pada Tabel 3 dan Tabel 4 .

Penelitian dilakukan di perairan teluk Palabuhanratu, Sukabumi yang dilaksanakan selama enam hari dari tanggal 24 Agustus sampai 30 Agustus 2014. Tahapan pengoperasian rumpon portable dimulai dengan pembukaan rangka rumpon portable, pemasangan atraktor dan pemberat pada tali utama, pemasangan tali utama pada kabel penyangga rangka rumpon portable.

Pengoperasian rumpon portable dimulai dengan mengikat rumpon pada pada kapal. Daerah pelepasan rumpon dipilih berdasarkan tanda potensi sumberdaya ikan seperti burung dan riak. Pemilihan lokasi tersebut dimaksudkan agar pengoperasian rumpon portable optimal.

Operasi penangkapan ikan dilakukan sebanyak empat kali ulangan dalam satu hari, dengan waktu operasi selama tiga jam. Pengoperasian awal dimulai pada pukul 05:00 WIB. Operasi penangkapan ikan dimulai setelah 1 jam rumpon diturunkan. Hal tersebut bertujuan agar proses pengoprasian rumpon terlebih dahulu dilaksanakan. Tahapan selanjutnya adalah operasi penangkapan ikan dengan alat tangkap pancing ulur yang telah dipersiapkan sebelumnya sebanyak lima unit pancing ulur. Penurunan (setting) alat tangkap dilakukan secara bersamaan di sisi kiri, kanan dan belakang kapal yang kemudian dilanjutkan dengan pengangkatan alat tangkap pancing (hauling) ketika sudah terasa ada ikan yang memakan pancing. Proses setting dan hauling berlangsung selama dua jam di sekitar rumpon portable. Ikan hasil tangkapan di sekitar rumpon portable terdiri dari 5 jenis spesies ikan yang berjumlah 185 ekor. Sebanyak 111 ekor yellowfin tuna (Thunnus albacares), 68 ekor cakalang (Katsuwonus pelamis), 4 ekor lemadang (mahi-mahi), 1 ekor salem (rainbow runner) dan 1 ekor jelidin.

Data hasil tangkapan perhari selama penelitian memiliki sebaran yang fluktuatif; 1) hari pertama memperoleh hasil tangkapan berjumlah 17 ekor; 2) hari kedua sebanyak 27 ekor; 3) hari ketiga sebanyak 59 ekor; 4) hari keempat sebanyak 35 ekor; 5) hari kelima sebanyak 31 ekor; dan 6) pada hari keenam sebanyak 16 ekor (Gambar 4).

Data hasil tangkapan perhari selama penelitian dibedakan per masing-masing spesies hasil tangkapan. Hari pertama mendapatkan hasil tangkapan tuna sebanyak 9 ekor, cakalang sebanyak 7 ekor dan lemadang sebanyak 1 ekor. Hari kedua mendapatkan tuna sebanyak 16 ekor dan cakalang sebanyak 11 ekor. Hari ketiga mendapatkan tuna sebanyak 32 ekor, cakalang sebanyak 25 ekor dan lemadang sebanyak 2 ekor. Hari keempat mendapatkan tuna sebanyak 23 ekor, cakalang sebanyak 9 ekor, lemadang sebanyak 1 ekor, salem sebanyak 1 ekor dan ikan jelidin sebanyak 1 ekor. Hari kelima mendapatkan tuna sebanyak 21 ekor dan cakalang sebanyak 10 ekor. Hari keenam mendapatkan tuna sebanyak 10 ekor dan cakalang sebanyak 6 ekor (Gambar 5)

Data tangkapan siang dan malam selama penelitian memiliki perbandingan yang cukup drastis. Pagi hingga sore hari (pukul 05:00-17:00 WIB) mendominasi hasil tangkapan sebesar 96\%, sedangkan pada malam hari (pukul 17:00-00:00 WIB) hasil tangkapan hanya 4\% (Gambar 6).

Dari keseluruhan hasil tangkapan ikan disekitar rumpon terdapat dua jenis ikan yang termasuk ke dalam ikan ekonomis penting, yaitu ikan tuna dan ikan cakalang. Oleh karena itu, hanya dua jenis tersebut yang dianalisis sebaran panjangnya.

Ukuran panjang ikan tuna yang tertangkap disekitar rumpon portable berkisar $39.30 \mathrm{~cm}-107.30 \mathrm{~cm}$. Frekuensi panjang tertinggi terdapat pada selang kelas $48.30 \mathrm{~cm}-57.20 \mathrm{~cm}$. Sebaran panjang ikan tuna dapat dilihat pada Gambar 7.

Ukuran bobot ikan tuna yang tertangkap disekitar rumpon portable berkisar $0.58 \mathrm{~kg}-15.77 \mathrm{~kg}$. Frekuensi berat tertinggi terdapat pada selang kelas 0.58 
kg-2.57 kg. Sebaran berat ikan tuna dapat dilihat pada Gambar 8.

Ukuran panjang ikan cakalang yang tertangkap disekitar rumpon portable berkisar $40 \mathrm{~cm}-73.10 \mathrm{~cm}$. Frekuensi panjang tertinggi terdapat pada selang kelas $40 \mathrm{~cm}$ $44.79 \mathrm{~cm}$. Sebaran panjang ikan cakalang dapat dilihat pada Gambar 9.

Ukuran bobot ikan cakalang yang tertangkap disekitar rumpon portable berkisar $0.45 \mathrm{~kg}-7.80 \mathrm{~kg}$. Frekuensi bobot tertinggi terdapat pada selang kelas $0.45 \mathrm{~kg}$ $1.54 \mathrm{~kg}$. Sebaran bobot ikan cakalang dapat dilihat pada Gambar 10 yang ditangkap menggunakan alat tangkap pancing ulur yang digunakan dalam penelitian ditampilkan pada Gambar 11 .

Hasil tangkapan ikan keseluruhan yang tertangkap mengounakan pancing ulur dalam penelitian ini berjumlah 176 ekor, terdiri atas ikan tuna sirip kuning (Thunus albacares), cakalang (Katsuwonus pelamis), dan lamadang (Coryphaena hippurus). Tiga jenis hasil tangkapan ini merupakan kelompok ikan yang sudah umum tertangkap pancing nelayan Palabuhanratu. Jenis hasil tangkapan ikan tersebut merupakan jenis pelagis. Thunus albacares termasuk dalam kategori ikan pelagis besar, sedangkan cakalang dan lemadang termasuk dalam kategori ikan pelagis kecil.

Rata-rata pengoperasian alat tangkap pancing ulur dilakukan 2-3 jam, hal ini dikarenakan saat dilakukannya operasi penangkapan beberapa faktor yang mempengaruhi operasional alat tangkap yakni faktor cuaca seperti angin dan gelombang besar yang tidak memungkinkan melanjutkan kegiatan penangkapan ikan pada waktu dan hari tersebut. Selain itu, faktor lain yang mempengaruhi ialah saat operasi penangkapan berlangsung beberapa alat tangkap ada yang terputus sehingga perlu adanya perbaikan pada alat tangkap. Frekuensi suara yang berasal dari yang digunakan dalam penelitian adalah frekuensi suara rendah $10 \mathrm{~Hz}-1.000 \mathrm{~Hz}$ dan frekuensi suara sedang $1.000 \mathrm{~Hz}-20.000$ $\mathrm{Hz}$. Pembagian frekuensi suara didasarkan pada indera pendengaran untuk ikan pelagis besar seperti ikan tuna, cakalang dan lemadang. Jumlah hasil tangkapan per frekuensi suara dapat dilihat pada Gambar 12 .

Jumlah hasil tangkapan harian dengan menggunakan frekuensi suara yang berbeda sangat bervariasi. Hasil tangkapan terbanyak sebesar 28 ekor diperoleh pada hari ke-4 untuk rumpon portable yang menggunakan frekuensi suara rendah dan pada hari ke-3 sebesar 23 ekor untuk rumpon portable yang menggunakan frekuensi suara sedang (Gambar 13). Jumlah hasil tangkapan per hari per masing-masing spesies dapat dilihat pada Gambar 14.

Total hasil tangkapan uji coba lapangan berdasarkan perbedaan waktu pengambilan data hasil tangkapan yang dilakukan selama 6 hari dapat dilihat pada Gambar 15.



Gambar 2. Rumpon portable dalam keadaan terbuka 


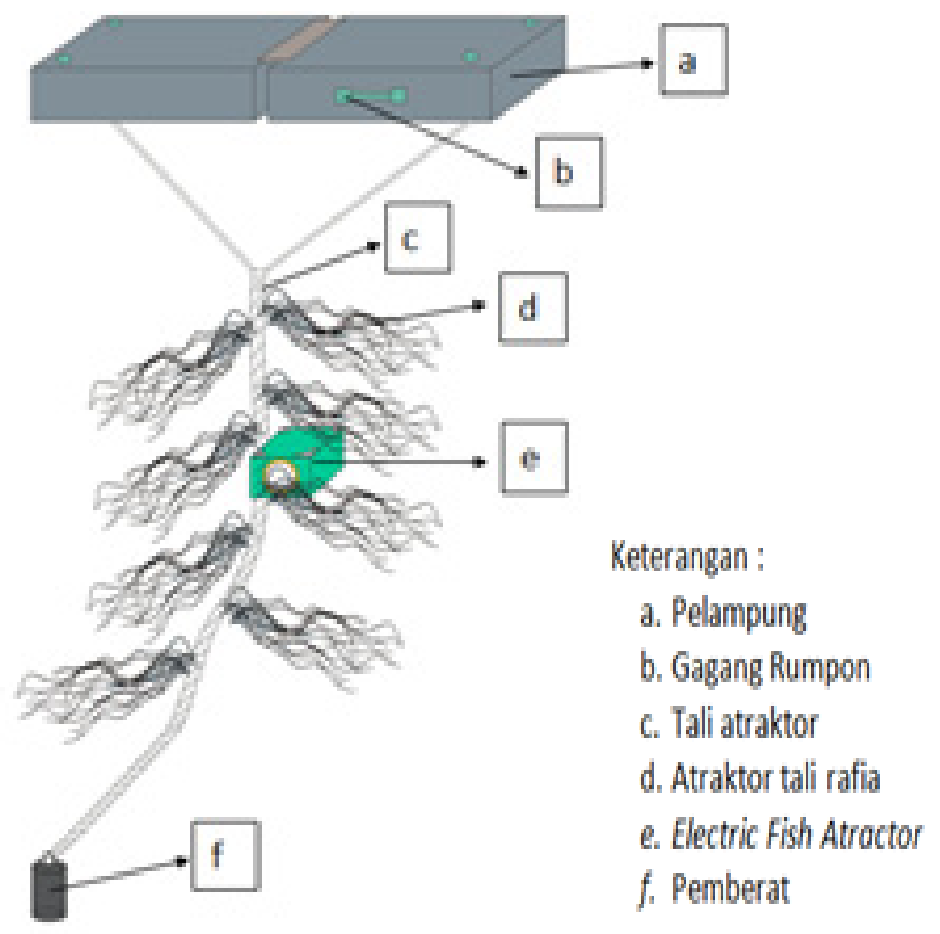

Gambar 3. Rumpon portable dalam keadaan terbuka dan siap dioperasikan

Tabel 3. Data extra bouyancy rumpon portable pada air tawar

\begin{tabular}{|c|c|c|c|c|c|c|c|c|c|c|}
\hline nama benda & $\begin{array}{c}\text { volume } \\
\text { (em') }\end{array}$ & $\begin{array}{c}\text { w (berat } \\
\text { benda) } \\
\text { grm }\end{array}$ & $\begin{array}{c}\text { massa } \\
\text { jenis } \\
\text { air } \\
\text { tawar }\end{array}$ & jumlah & satuan & $\begin{array}{l}\text { gaya } \\
\text { apung }\end{array}$ & $\begin{array}{c}\text { gaya } \\
\text { tenggelam }\end{array}$ & $\begin{array}{l}\text { jumlah } \\
\text { total } \\
\text { apung }\end{array}$ & $\begin{array}{c}\text { jumlah } \\
\text { total } \\
\text { tenggelam }\end{array}$ & $\begin{array}{c}\text { Extra } \\
\text { buoyan } \\
\text { cy }\end{array}$ \\
\hline pemberat & 1653,75 & 10000,00 & 1 & 1 & buah & 1653,75 & 8346,25 & $\begin{array}{r}1653,75 \\
120000,0\end{array}$ & 8346,25 & $173 \%$ \\
\hline pelampung & 30000,00 & 950,00 & 1 & 4 & buah & 30000,00 & $-29250,00$ & 0 & 117000,00 & \\
\hline bambu 1 & 3108,00 & 630,00 & 1 & 6 & buah & 3108,00 & $-2478,00$ & 18648,00 & $-14868,00$ & \\
\hline bambu 2 & 593,01 & 470,00 & 1 & 2 & buah & 593,01 & $-123,01$ & 1186,02 & $-246,02$ & \\
\hline bambu 3 & 382,40 & $350, \infty$ & 1 & 4 & buah & 382,40 & $-32,40$ & 1529,60 & $-129,60$ & \\
\hline bambu 4 & 75,81 & 65,00 & 1 & 4 & buah & 75,81 & $-10,81$ & 303,24 & $-43,24$ & \\
\hline kaya 1 & 3024,00 & 1450,00 & 1 & 8 & buah & 3024,00 & $-1574,00$ & 24192,00 & $-12592,00$ & \\
\hline kaya 2 & 520,00 & 450,00 & 1 & 8 & buah & 520,00 & $-70,00$ & 4160,00 & $-560,00$ & \\
\hline kayu 3 & 751,10 & $650, \infty 0$ & 1 & 4 & buah & 751,10 & $-101,10$ & 3004,40 & $-404,40$ & \\
\hline kayu 4 & 544,18 & $480, \infty 0$ & 1 & 8 & buah & 544,18 & $-64,18$ & 4353,44 & $-513,44$ & \\
\hline kayu 5 & 3120,00 & $1530, \infty$ & 1 & 1 & buah & 3120,00 & $-1590,00$ & 3120,00 & $-1590,00$ & \\
\hline kayu 6 & 2509,20 & 1320,00 & 1 & 2 & $\begin{array}{l}\text { buah } \\
\text { blogra }\end{array}$ & 2509,20 & $-1189,20$ & 5018,40 & $-2378,40$ & \\
\hline paku & 0,00 & 1000,00 & 1 & 1 & $\mathrm{~m}$ & 0,00 & 1000,00 & 0,00 & 1000,00 & \\
\hline jaring & $0, \infty$ & 460,00 & 1 & 4 & meter & 0,00 & 460,00 & 0,00 & 1840,00 & \\
\hline $\begin{array}{l}\text { tali rafia } \\
\text { tali PE } 0,3\end{array}$ & $0, \infty$ & 610,00 & 1 & 1 & gulung & 0,00 & 610,00 & $0, \infty$ & 610,00 & \\
\hline $\begin{array}{l}\text { inci } \\
\text { tali PE 0,75 }\end{array}$ & 28,26 & 1,32 & 1 & 5,15 & meter & 28,26 & $-26,94$ & 145,54 & $-138,74$ & \\
\hline $\begin{array}{l}\text { inci } \\
\text { tali pud } 1\end{array}$ & 176,63 & 158,03 & 1 & 12,6 & meter & 176,63 & $-18,59$ & 2225,48 & $-234,28$ & \\
\hline \multirow[t]{2}{*}{ inci } & 490,63 & 202,45 & 1 & 10 & meter & 490,63 & $-288,17$ & $\begin{array}{r}4906,25 \\
194446,1\end{array}$ & $-2881,71$ & \\
\hline & & & & & & & TOTAL & 14 & 141783,58 & \\
\hline
\end{tabular}


Tabel 4. Data extra bouyancy rumpon portable pada air laut

\begin{tabular}{|c|c|c|c|c|c|c|c|c|c|c|}
\hline \multirow[b]{2}{*}{ nama benda } & \multirow[b]{2}{*}{$\begin{array}{c}\text { volume } \\
\left(\mathrm{cm}^{7}\right)\end{array}$} & \multicolumn{4}{|c|}{ mass } & \multirow[b]{2}{*}{$\begin{array}{c}\text { gaya } \\
\text { apung }\end{array}$} & \multirow[b]{2}{*}{$\begin{array}{c}\text { gaya } \\
\text { tenggela } \\
\text { m }\end{array}$} & \multirow[b]{2}{*}{$\begin{array}{l}\text { jumlah } \\
\text { total } \\
\text { apung }\end{array}$} & \multirow[b]{2}{*}{$\begin{array}{l}\text { jumlah total } \\
\text { tengaelam }\end{array}$} & \multirow[b]{2}{*}{$\begin{array}{c}\text { Extra } \\
\text { buoyancy }\end{array}$} \\
\hline & & $\begin{array}{c}\text { w (berat } \\
\text { benda) } \\
\text { arm }\end{array}$ & $\begin{array}{c}\text { a } \\
\text { ienis } \\
\text { air } \\
\text { tawar }\end{array}$ & iumlah & satuan & & & & & \\
\hline pemberat & 1653,75 & 10000,00 & 1,025 & 1 & buala & 1695,09 & 8304,91 & 1695,09 & 8304,91 & $173 \%$ \\
\hline pelampung & 30000,00 & $960, \infty 0$ & 1,025 & 4 & buah. & 30750,00 & $-29250,00$ & 120000,00 & $-117000,00$ & \\
\hline bambu 1 & 3108,00 & 630,00 & 1,025 & 6 & bualo. & 3185,70 & $-2655,70$ & 19114,20 & $-16334,20$ & \\
\hline bambu 2 & 593,01 & 470,00 & 1,025 & 2 & bual & 607,84 & $-137,84$ & 1215,67 & $-275,67$ & \\
\hline bambu 3 & 382,40 & 350,00 & 1,025 & 4 & buah & 391,96 & $-41,96$ & 1567,84 & $-167,84$ & \\
\hline bambu 4 & 75,81 & 65,00 & 1,025 & 4 & buah & 77,71 & $-12,71$ & 310,82 & $-50,82$ & \\
\hline kayu 1 & 3024,00 & 1450,00 & 1,025 & 8 & buah & 3099,60 & $-1649,60$ & 24796,80 & $-13196,80$ & \\
\hline kayu 2 & 520,00 & 450,00 & 1,025 & 8 & buah. & 533,00 & $-83,00$ & 4264,00 & $-664,00$ & \\
\hline kaxu 3 & 751,10 & 660,00 & 1,025 & 4 & buah & 769,88 & $-119,88$ & 3079,51 & $-479,51$ & \\
\hline $\operatorname{kayu} 4$ & 544,18 & 480,00 & 1,025 & 8 & buah. & 567,78 & $.77,78$ & 4462,28 & $-622,28$ & \\
\hline $\operatorname{kayu} 5$ & 3120,00 & 1530,00 & 1,025 & 1 & buah. & $3198, \infty 0$ & $-1668,00$ & 3198,00 & $-1668,00$ & \\
\hline kayu 6 & 2509,20 & 1320,00 & 1,025 & 2 & buah & 2571,93 & $-1251,93$ & 5143,86 & $-2503,86$ & \\
\hline paku & 0,00 & 1000,00 & 1,025 & 1 & kilogram & 0,00 & 1000,00 & 0,00 & 1000,00 & \\
\hline jaring & 0,00 & 460,00 & 1,025 & 4 & meter & 0,00 & 460,00 & 0,00 & 1840,00 & \\
\hline tali rafia & 0,00 & $610, \infty 0$ & 1,025 & 1 & suluos & $0, \infty 0$ & 610,00 & 0,00 & 610,00 & \\
\hline \multicolumn{11}{|l|}{ tali PE 0,3 } \\
\hline inci & 28,26 & 1,32 & 1,025 & 6,16 & meter & 28,97 & $-27,65$ & 149,18 & $-142,38$ & \\
\hline \multicolumn{11}{|l|}{ tali PE 0,75} \\
\hline inci & 176,63 & 158,03 & 1,025 & 12,6 & meter & 181,04 & $-23,01$ & 2281,11 & $-289,92$ & \\
\hline \multirow[t]{2}{*}{ tali pyd 1 inci } & 490,63 & 202,45 & 1,025 & 10 & meter & 502,89 & $-300,44$ & 5028,91 & $-3004,37$ & \\
\hline & & & & & & & TOTAL & 196307,27 & $-143644,73$ & \\
\hline
\end{tabular}

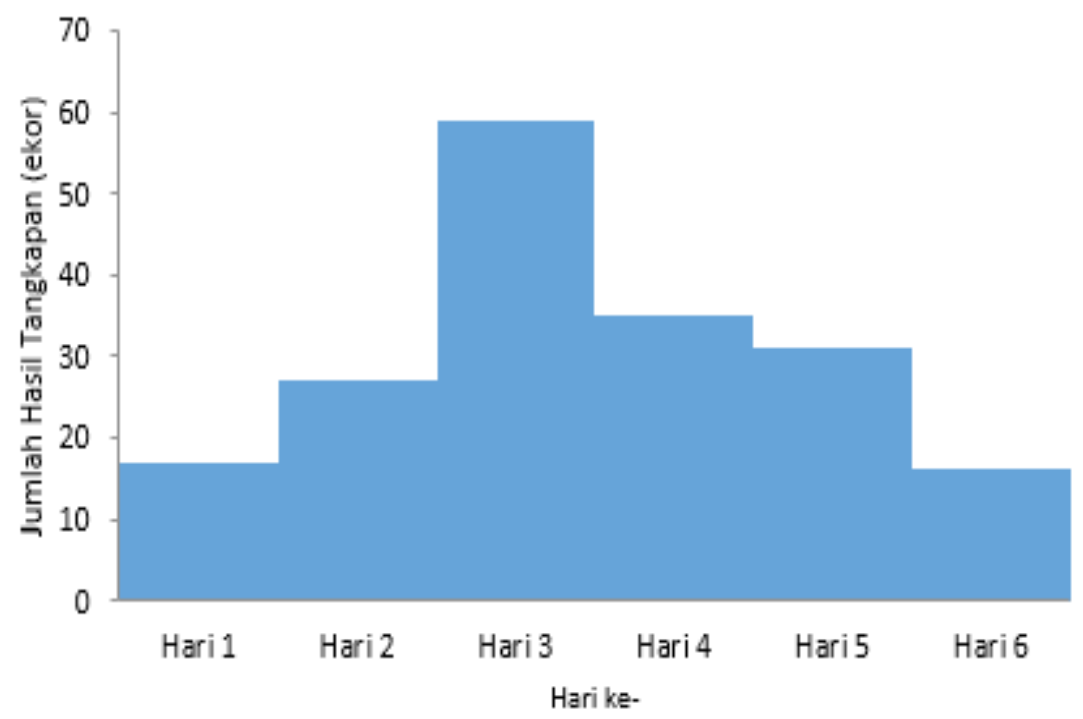

Gambar 4. Hasil tangkapan berdasarkan hari operasi penangkapan 


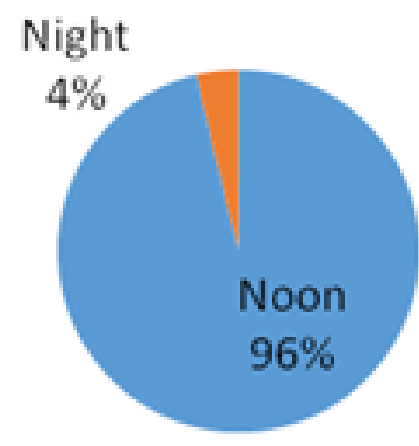

Gambar 6. Diagram perbandingan hasil tangkapan berdasarkan waktu

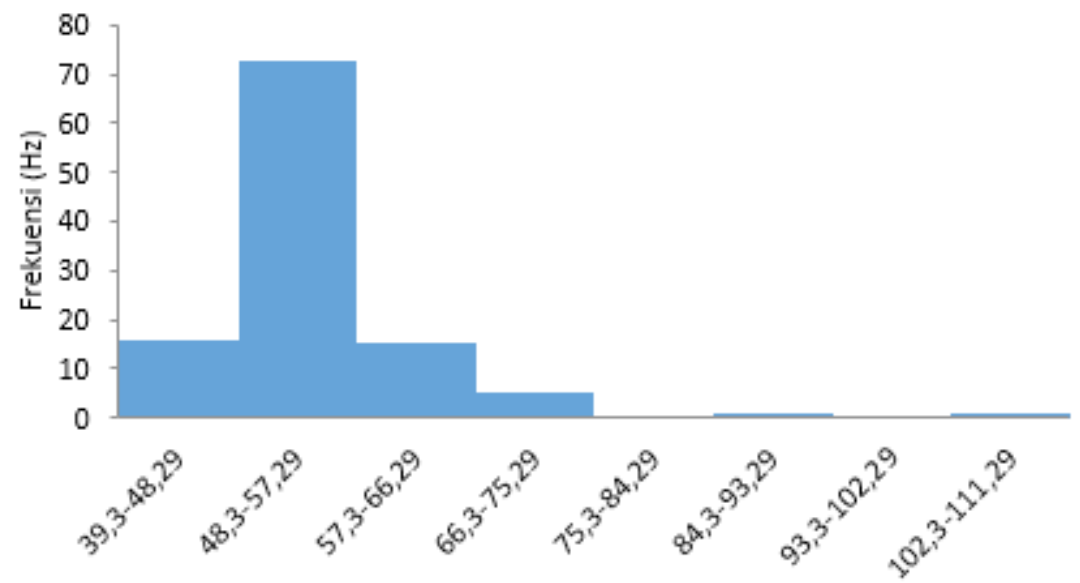

Gambar 7. Sebaran kelas panjang $(\mathrm{cm})$ ikan tuna

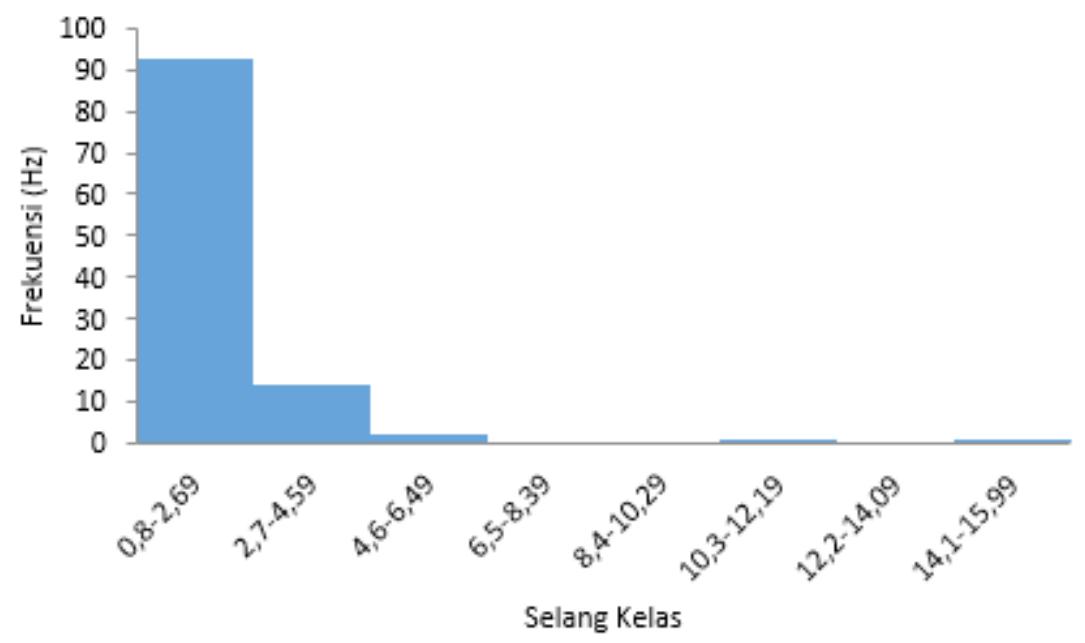

Gambar 8. Sebaran kelas bobot (kg) ikan tuna 




Gambar 9. Sebaran kelas panjang $(\mathrm{cm})$ ikan cakalang

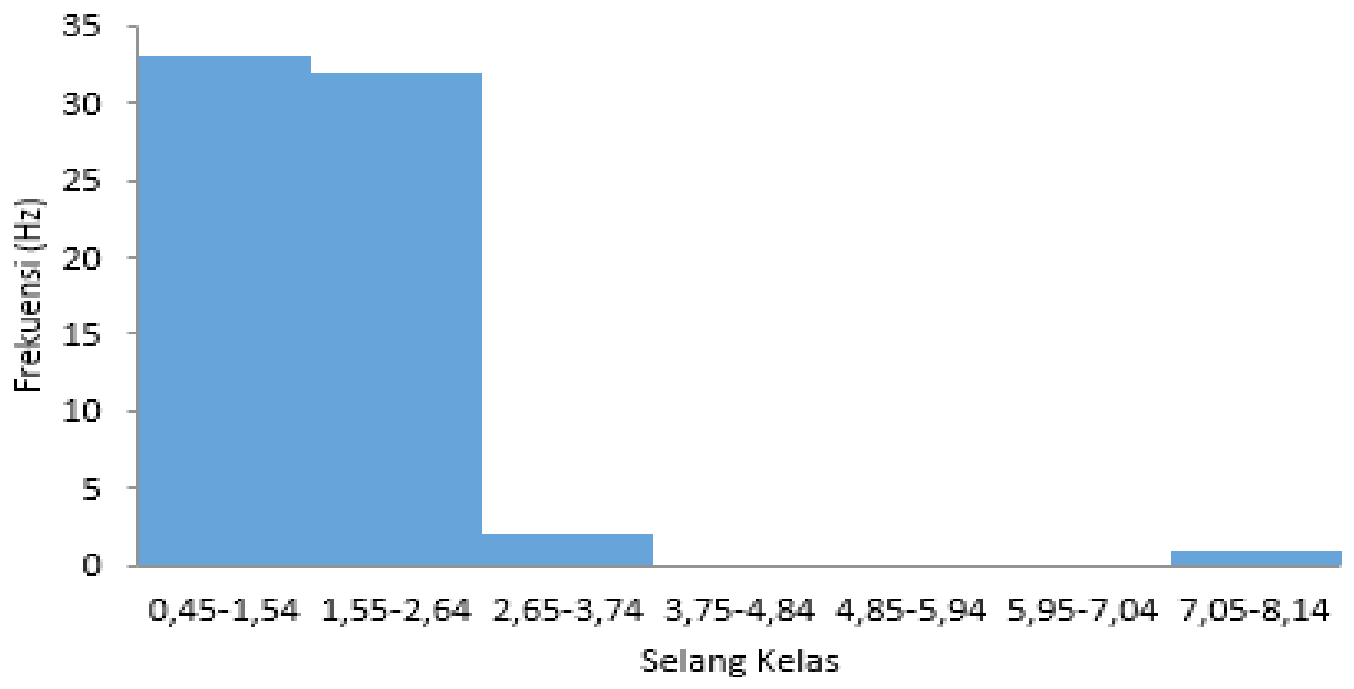

Gambar 10. Sebaran kelas bobot (kg) ikan cakalang 


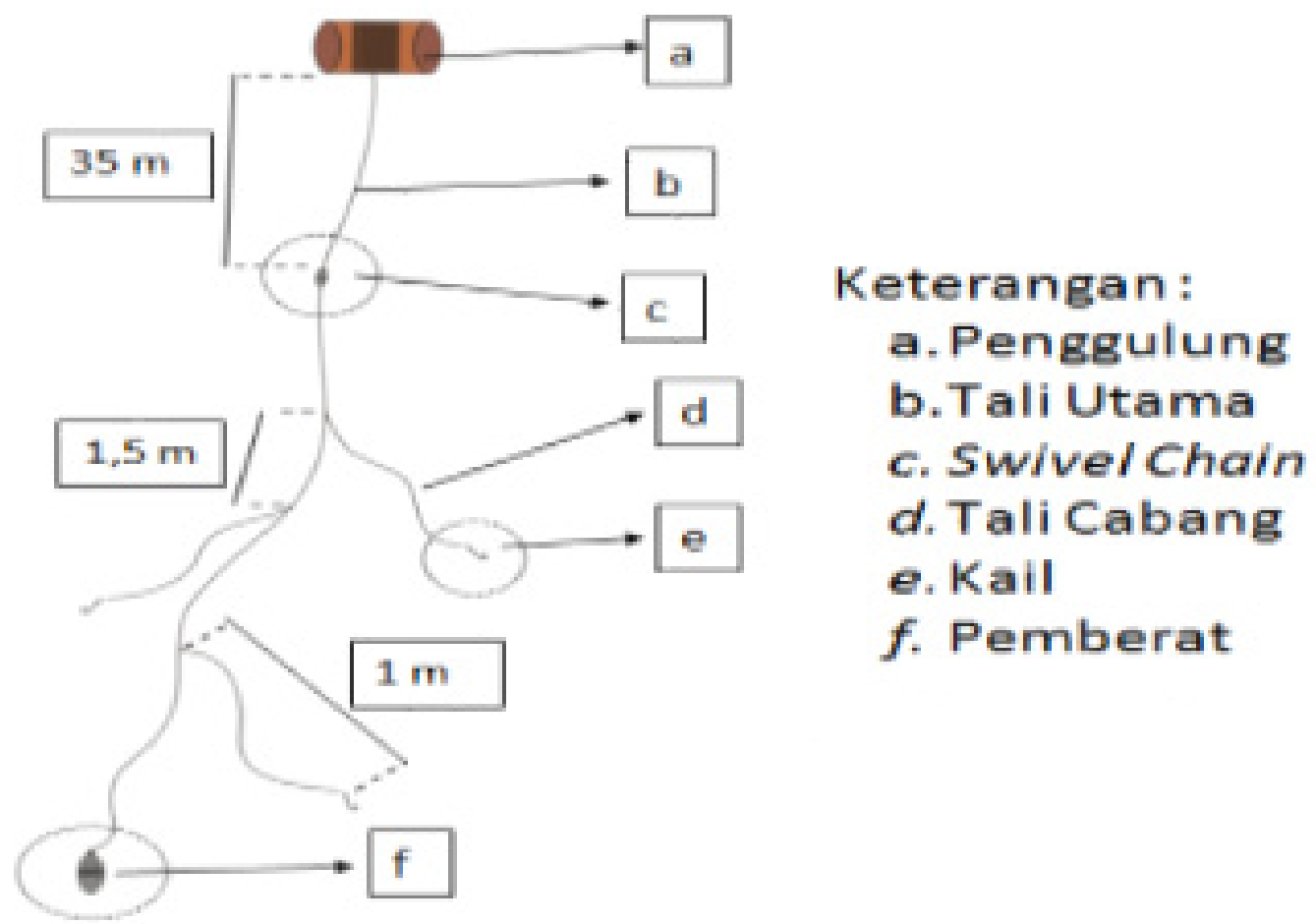

Gambar 11. Konstruksi alat tangkap pancing ulur

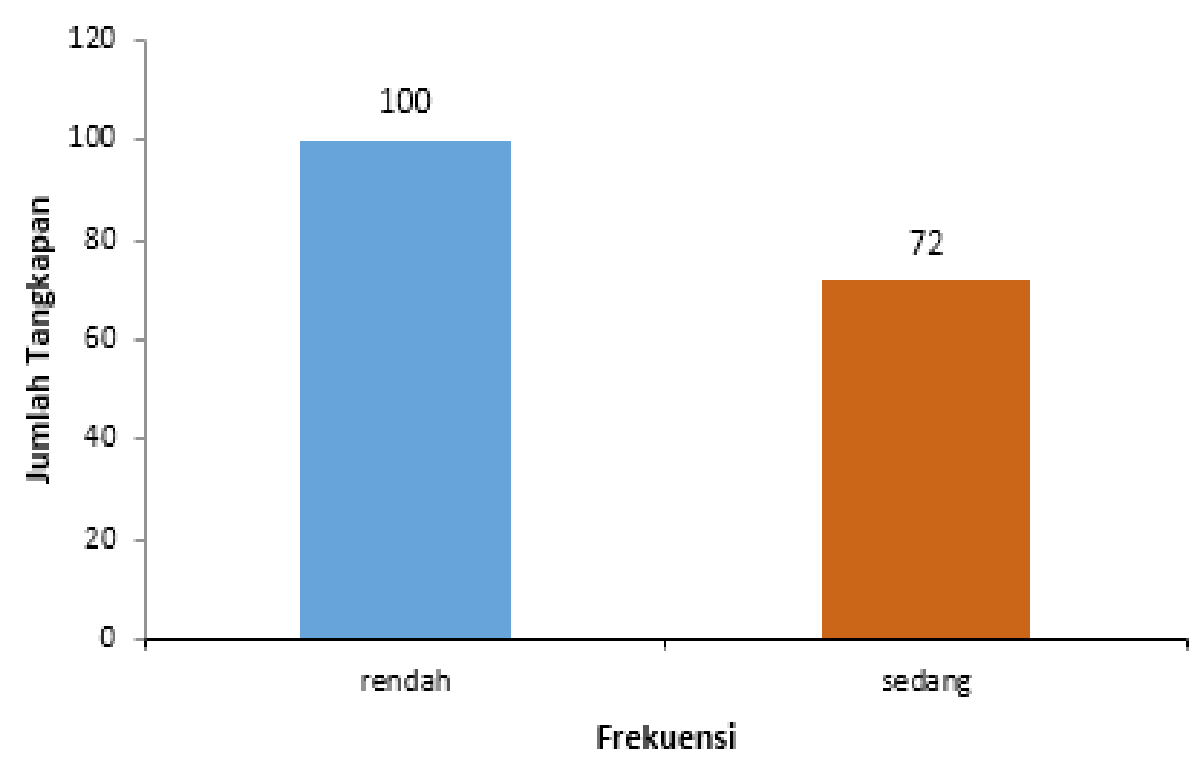

Gambar 12. Jumlah tangkapan berdasarkan frekuensi suara 




Gambar 13. Jumlah tangkapan harian berdasarkan frekuensi suara yang digunakan



Rendah

- Sedang

Gambar 14. Jumlah tangkapan masing-masing spesies berdasarkan frekuensi suara yang digunakan 